\title{
Lower Pitch Voice Produce by Effort Sound in Previously Uvulectomized Children
}

\author{
SABO, Ahmed Mohammed ${ }^{1} \quad$ JIBRIN Yusuf Bara ${ }^{2} \quad$ GALAM Nanyak Zingfa $^{1}$ \\ YARUBE Isyaku Umar ${ }^{3} \quad$ MSHELIA Paul Philemon ${ }^{4}$ \\ 1. Department of Human Physiology, Faculty of Basic Medical Sciences, \\ College of Health Sciences, University of Jos, Jos-Nigeria \\ 2. Department of Medicine, Abubakar Tafawa Balewa University Teaching Hospital Bauchi. Bauchi-Nigeria \\ 3. Department of Physiology, Faculty of Basic Medical Sciences, \\ College of Health Sciences, Bayero University,Kano-Nigeria \\ 4. Department of Human Physiology, College of Medical Sciences, \\ Abubakar Tafawa Balewa University Bauchi. Bauchi-Nigeria
}

\begin{abstract}
The palatine uvula is conic projection composing of soft connective tissue which has a number of racemose glands. It hangs from the posterior edge of the middle of the soft palate of the roof of the mouth. It has circular muscle fibres at its base and helps in closing the nasopharynx during deglutition. Copious secretion from the uvula helps moisten the larynx and vocal cord to maintain quality speech. In the Hausas' culture in Northern Nigeria, the uvula is highly demonized and blamed for a lot of health problems and risk of death and so all infants must 'proactively' undergo uvulectomy on the 7th day after birth, with few exceptions. This study aims at evaluating the effect of uvulectomy on pitch quality of effort sounds of young children between 2 to 11 years of age. Eighty subjects were divided into two groups of 40 uvulectomized and 40 non-uvulectomized children which were further subdivided into various age ranges of equal mix of male and female. Audio frequency analyzer software is used to conduct the test and the result shows a reduction in frequency of the sounds produced by uvulectomized subjects, $\mathrm{p}<0.05$. Uvulectomy does affect the quality of sound produced in children giving a significant lower pitch quality.
\end{abstract}

Keywords: Uvula, Uvulectomy, Effort Sound, Frequency, Pitch

DOI: $10.7176 / \mathrm{JHMN} / 90-01$

Publication date:June $30^{\text {th }} 2021$

\section{INTRODUCTION}

The quality of sound produce by human largely depends on the age of the pre-pubertal child, the size of the vocal cord and the respiratory effort exerted in production of the sound. The ability to vocalize and produce sound to the level of speech in man has evolved in animals for the purpose of communication, both in conveying the message of danger and distress, to cry for support in hunting etc. The quality of vocalization may convey different messages in the mind of the both chilren and adults. For example, the high pitch sound of a baby seems an extremely distressing sound to both the female and male parents, even in humans, a sound quality that serves the purpose of enabling care.

The palatine uvula is conic projection composing of soft connective tissue which has a number of racemose glands. It hangs from the posterior edge of the middle of the soft palate of the roof of the mouth. It has circular muscle fibres at its base and helps in closing the nasopharynx during deglutition. Copious secretion from the uvula helps moisten the larynx and vocal cord to maintain quality speech. In certain cultures in Northern Nigeria, the Uvula, which every child is born with is viewed suspicion as an undesirable Anatomical structure that causes vomiting in newborns and even older that may also result in infection and abscess formation that may rupture and lead to death. There is no literature or credible medical report to support that assertion. It may only be viewed as fear mongering that supports a culture.

Thus, in the Hausas' culture in Northern Nigeria, the uvula is highly demonized and wrongly blamed for a lot of health problems and risk of death and so all infants must 'proactively' undergo Uvulectomy. Apart from the immediate complication of massive haemorrhage from the Uvula stump and the loss of blood that leads to this case specific high infants mortality, late complication may involve altered sound quality aside risk of vulnerability to repeated choking during deglutition

\section{AIM AND OBJECTIVE}

This study aims at studying the effect of uvulectomy on pitch quality of effort sounds of young children between 2 to 11 years of age.

\section{MATERIAL AND METHOD}

Forty subjects were divided into two groups of twenty uvulectomized and twenty non-uvulectomized children after ethical clearance and permission from the parents that accompanied them during the tests. The two groups, each 
with equal mix of male and female, were further subdivided into various age ranges for this non-intervention study. Audio frequency analyzer software (Sound Oscilloscope 2.0) is used to conduct the test in a sound proof studio. Five successive readings were taken for each subject and a rest interval of one minute is given for each reading. The average for each individual is recorded as part of the initial data. The effort sound of choice was maximal and loud screechy sound enough for the uvula to constitute acoustic impedance to the flow of air.

Table 1.

Table Showing Sound Frequencies distribution among Non-Uvulectomized and Uvulectomized Male children. RESULTS

\begin{tabular}{ccccc}
\hline & & & EFFORT SOUND FREQUENCY IN NON- & EFFORT \\
S/No & SEX & AGE(years) & SVULECTOMIZED CHILDREN (Hz) & FREQUENCY IN \\
UVULECTOMIZED CHILDREN (Hz)
\end{tabular}

$\mathrm{T}$ test $\mathrm{P}$, value $<0.001$ There is significant difference between the frequencies of uvulectomizedand and nonuvulectomized male children.

Table 2

.Table Showing Sound Frequencies distribution among Non-Uvulectomized and UvulectomizedFemale children.

\begin{tabular}{|c|c|c|c|c|}
\hline S/No & SEX & AGE(years) & $\begin{array}{l}\text { EFFORT SOUND FREQUENCY IN NON- } \\
\text { UVULECTOMIZED CHILDREN (Hz) }\end{array}$ & $\begin{array}{l}\text { EFFORT SOUND FREQUENCY IN } \\
\text { UVULECTOMIZED CHILDREN }(\mathrm{Hz})\end{array}$ \\
\hline 1 & $\mathrm{~F}$ & 4 & 516 & 200 \\
\hline 2 & $\mathrm{~F}$ & 4 & 498 & 300 \\
\hline 3 & $\mathrm{~F}$ & 4 & 501 & 312 \\
\hline 4 & $\mathrm{~F}$ & 4 & 512 & 399 \\
\hline 5 & $\mathrm{~F}$ & 5 & 514 & 381 \\
\hline 6 & $\mathrm{~F}$ & 5 & 493 & 323 \\
\hline 7 & $\mathrm{~F}$ & 5 & 477 & 318 \\
\hline 8 & $\mathrm{~F}$ & 6 & 507 & 314 \\
\hline 9 & $\mathrm{~F}$ & 6 & 433 & 338 \\
\hline 10 & $\mathrm{~F}$ & 6 & 445 & 412 \\
\hline 11 & $\mathrm{~F}$ & 7 & 299 & 351 \\
\hline 12 & $\mathrm{~F}$ & 7 & 259 & 240 \\
\hline 13 & $\mathrm{~F}$ & 7 & 520 & 490 \\
\hline 14 & $\mathrm{~F}$ & 8 & 308 & 401 \\
\hline 15 & $\mathrm{~F}$ & 8 & 411 & 281 \\
\hline 16 & $\mathrm{~F}$ & 8 & 389 & 368 \\
\hline 17 & $\mathrm{~F}$ & 9 & 480 & 492 \\
\hline 18 & $\mathrm{~F}$ & 9 & 329 & 218 \\
\hline 19 & $\mathrm{~F}$ & 11 & 506 & 381 \\
\hline 20 & $\mathrm{~F}$ & 11 & 537 & 295 \\
\hline
\end{tabular}

T test $\mathrm{P}$ value is, $\mathrm{P}<0.001$ There is significant difference between the frequencies of uvulectomized and nonuvulectomized female children. 


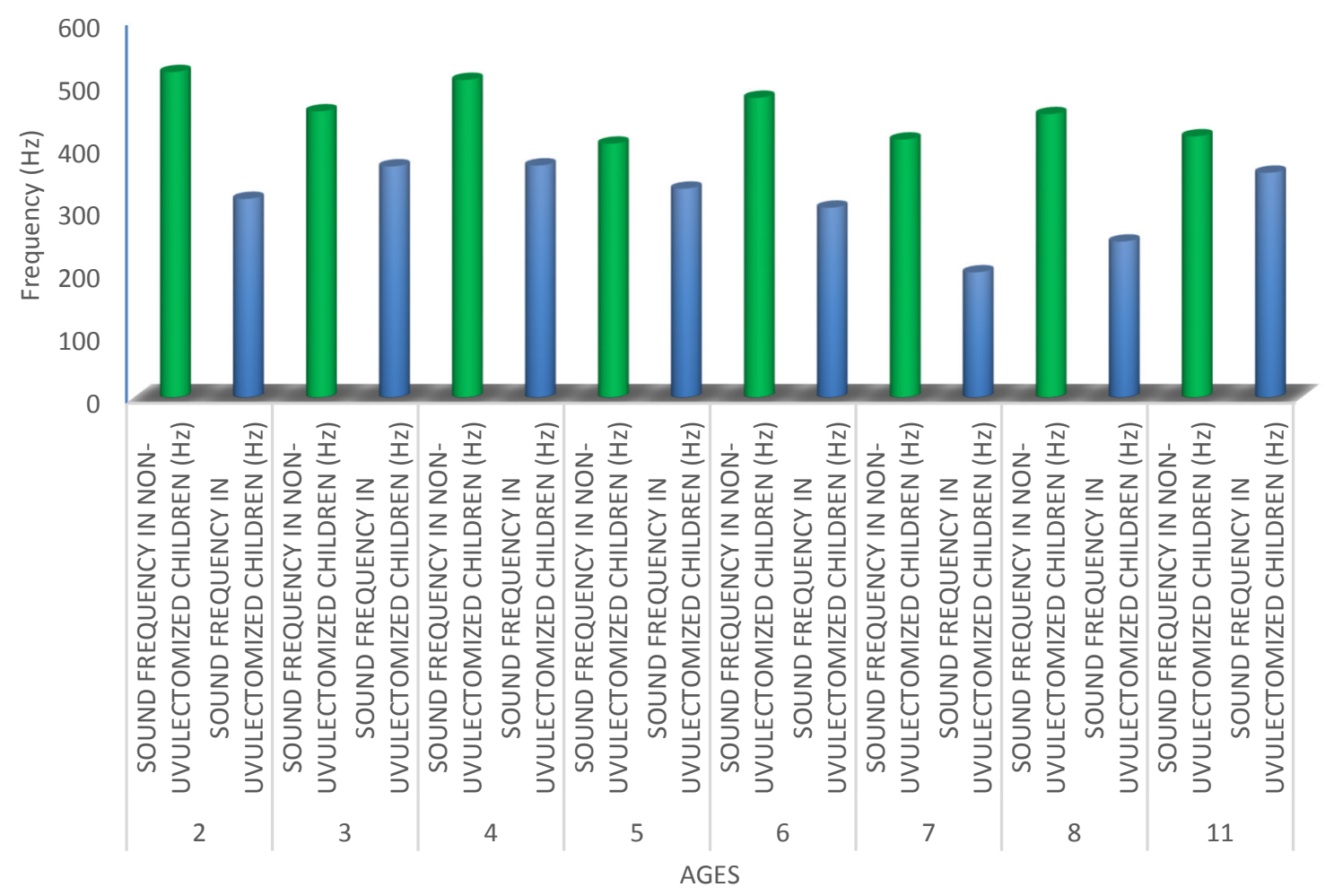

Figure 1.Bar chart showing Sound Frequencies distribution among Non-Uvulectomized and Uvulectomized children.

\section{DISCUSSION}

From the statistics and the $\mathrm{T}$ test conducted, the $\mathrm{P}$ value is $<0.001$. There is significant difference between the frequencies (pitch sound quality) of uvulectomized and non-uvulectomized children independent of sex. The difference in voice pitch between males and females is said to be less pronounced before puberty (Markova D, 2016). Pitch is determined by both nature and nurture.

While there are well recognized complications of uvulectomy both immediate and long term, as respectively exemplified by haemorrhage and difficult in closure of nasopharynx by the soft palate to which the uvula is anchored leading to frequent regurgitation of food out through the nose (Sawe et al. 2015), the effect on the quality of the voice in the long run has rarely been studied. The obvious reduction in pitch of the voice produced in response to uvulectomy has been demonstrated here. The uvula stands in the way of the turbulent air flowing out of the mouth during effort sound and the impedance creates this noticeable change. Pitch quality of the voice assists in recognizing and distinguishing individuals and also helps in estimating the age and gender of such individual.

The traditional uvulectomy in every child in Northern Nigeria has no recognizable benefit, only the lifethreatening immediate and long term complications. This work has demonstrated a clear loss of pitch in effort sound. If this lingers into adulthood it may impair the career of these individuals if they decide a career in music, opera, and high pitch scriptural recitation.

\section{CONCLUSION}

Children who had uvulectomy performed on them in their neonatal period usually end up with significantly lower frequency effort compared to non-uvulectomized

\section{RECOMMENDATION}

Cultural uvulectomy should be discouraged and further studies need to be conducted on this.

\section{REFERENCE}

1. Nigeria. J Laryngol Otol. Nov; 95(11): 1127-33

2. Ravesloot MJ and de Vries N (2011).' A good Sherpherd, but with Obstructive Sleep Apnoea Syndrome': Traditional Uvulectomy Case Series and Literature Review. 
3. Sawe HR, Mfinaga JA, Ringo FH, Mwafongo V, Reynold TA and Runyon MS. (2015). Morbidity and Mortality following Traditional Uvulectomy among Children Presenting to the Muhimbili National Hospital Emergency Department in Dar es Salaam, Tanzania.Emerg Med Int108247:1011552015

4. Adebola SO, Ogunkeyede SA, Obebe FA, Olaniyan OD, Fawole OB and Salman A (2016). Profile of Paediatric Traditional Uvulectomy in North-West Nigeria: The Need for Caution and Education. Int J PaediatrOtorhinolaryngol Sep: 88:194-8.

5. Markova D (2016). Age and Sex-related Variations in Vocal-tract Morphology and Voice Acoustics during Adolescence. HormBehav. May 8:81: 84-96. 